\title{
E-Cadherin and Syndecan-1 Expression in Patients With Advanced Non-small Cell Lung Cancer Treated With Chemoradiotherapy
}

\author{
PINELOPI GKOGKOU ${ }^{1}$, EVANGELIA PEPONI ${ }^{2}$, DIMITRIOS NTASKAGIANNIS ${ }^{2}$, SAMUEL MURRAY $^{3}$, \\ ASIMO DEMOU ${ }^{4}$, IOANNIS SAINIS ${ }^{5}$, ELLI IOAKEIM ${ }^{4}$, EVANGELOS BRIASOULIS ${ }^{6}$ and PERICLES TSEKERIS ${ }^{2}$ \\ ${ }^{1}$ Department of Radiation Oncology, Norfolk and Norwich University Hospital, Norwich, U.K.; \\ ${ }^{2}$ Department of Radiation Oncology, University Hospital of Ioannina, Ioannina, Greece; \\ ${ }^{3}$ Genekor SA, Athens, Greece; \\ ${ }^{4}$ Department of Pathology," Hatzikosta" Community Hospital, Ioannina, Greece; \\ ${ }^{5}$ Interscience Molecular Laboratory, Cancer Biobank Center, \\ University of Ioannina, University Campus, Ioannina, Greece; \\ ${ }^{6}$ Hematology Department and Interscience Molecular Laboratory, \\ Cancer Biobank Center, University of Ioannina, Ioannina, Greece
}

\begin{abstract}
Background/Aim: The aim of the study was to investigate whether E-cadherin and syndecan-1 are molecular markers of advanced non-small cell lung cancer (NSCLC). Patients and Methods: The expression of E-cadherin and syndecan-1 (SDC1) was examined immunohistochemically on tissue specimens of 64 patients, with stage III disease at presentation. The obtained expression data were correlated with clinical parameters. Results: Negative expression of SDCl was correlated with squamous histology $(p=0.002)$. Ecadherin positive expression was significantly associated with increased 2-year overall survival (OS) rate $(p=0.032)$. In the multivariate Cox analysis, performance status 0-1 was an independent predictor of $O S(p=0.001)$ and disease-free survival $(D F S)(p=0.001)$. E-cadherin expression was an independent predictor of OS $(p=0.007)$ and DFS $(p=0.029)$. Conclusion: E-cadherin might be a prognostic factor for OS and DFS in advanced stage NSCLC patients. Further investigations are needed for the establishment of E-cadherin and syndecan-1 as molecular markers, affecting treatment response and survival.
\end{abstract}

This article is freely accessible online.

Correspondence to: Pinelopi Gkogkou, MD, MSc, Ph.D., Department of Radiation Oncology, University Hospital of Ioannina, Stavrou Niarxou Ave. 1, 45500 Ioannina, Greece. Tel: +30 2651099472, Fax: +30 2651046617, e-mail: pinelopi.gkogkou@nnuh.nhs.uk

Key Words: E-cadherin, syndecan-1, radiotherapy, NSCLC, immunohistochemistry.
Non-small cell lung carcinoma (NSCLC) is considered the leading cause of malignancy-related mortality (1). Most patients with advanced stage disease receive concurrent chemoradiotherapy regimens that have improved the control of this treatment resistant tumor (2).

During the last years, intensive research has led to personalized treatments offered on the basis of molecular and pathological tumor characteristics. Identification of adhesion molecules involved in tumor growth and metastases is important for effective long-term management of the disease. Among these molecules, E-cadherin and syndecan-1 have been extensively investigated in a number of malignancies $(3,4)$.

E-Cadherin, a member of glycoproteins, has an essential morphogenic role in stabilizing epithelial cells by maintaining the intercellular connections through calcium-dependent adhesion (5). It also inhibits the metastatic potential of cancer cells by affecting their differentiation (6). Reduction or absence of E-cadherin is associated with decreased differentiation and increased metastatic ability in several malignancies $(7,8)$. Loss of E-cadherin expression leads to the epithelial-mesenchymaltransition (EMT) phenomenon, which is the process of epithelial transformation into mesenchymal cells, by loss of cell-cell adhesion $(3,9,10)$. In the process of EMT, deconstruction of cell polarity, reorganization of the cytoskeleton, and changes in signaling pathways increase motility and promote metastasis by enhancing cancer cell invasiveness, and thus resulting in dismal prognosis $(11,12)$.

Syndecan-1 (SDC1), a member of the transmembrane heparan sulfate proteoglycans (HSPGs), is involved in the morphogenetic process of cell-cell adhesion, by controlling interactions of extracellular cell matrix components and the 
ligands on the cell surface. Additionally, Syndecan-1 may act either as an inhibitor or a promoter of tumor progression, depending on the concertation of the signaling molecules between the cell surface and the extracellular matrix (13-15). It is also considered a co-receptor in signaling pathways, interacting with fibroblast growth factor receptor (FGFR), vascular endothelial growth factor receptor (VEGFR), and epidermal growth factor receptor (EGFR), affecting cell to cell interactions, altering signal transduction (16, 17), playing a role in cell proliferation, adhesion, migration, and angiogenesis $(13,18)$. SDC1 is highly expressed in epithelial malignancies, while it is reduced during malignant transformation of various epithelia, leading to mesenchymal characteristics and loss of the epithelial phenotype. Loss of SDC1 expression may be the hallmark step to EMT (19).

The aim of this study was to investigate the expression of E-cadherin and SDC1 in advanced stage NSCLC patients treated with chemoradiotherapy. The relationship of these molecules with other clinicopathologic factors of the disease was also examined.

\section{Patients and Methods}

Study design and patient population. Sixty-four (64) patients with inoperable advanced stage NSCLC were retrospectively evaluated. Data were collected regarding host (age, sex, smoking history), tumor ( $\mathrm{T}$ and $\mathrm{N}$ classification, histological grade and type) and treatment regimen (chemotherapy, radiotherapy). The disease was staged according to the 2017 American Joint Committee on Cancer (AJCC) staging classification. Histological typing was based on WHO classification. All patients had adequate medical records obtained during a meticulous follow up.

Ethical approval (Study number: 1322, School of Medicine, University of Ioannina, Greece) was obtained from the local ethics committee of the University Hospital of Ioannina. All patients were informed about the nature of the study and signed an informed consent. Formalin-fixed paraffin embedded tissue specimens were available.

Radiation therapy (RT) was performed using three-dimensional (3D) conformal techniques, with $6 \mathrm{MV}$ photons, including primary tumor and lymph nodes. The mean biologically equivalent dose delivered to the planning target volume (PTV) was $60 \mathrm{~Gy}$. The prescribed dose encompassed at least $95 \%$ of the PTV. No more than $20 \%$ of any PTV would receive $>110 \%$ of its prescribed dose, while no more than $1 \%$ of any PTV would receive $<93 \%$ of the desired dose. Cisplatin-based chemotherapy was administered either concurrently or sequentially to RT.

Immunohistochemistry. Immunostaining with monoclonal antibodies against E-cadherin (CM170B, Biocare Medical, CA, USA) and SDC1 (CD138) (clone DL-101, Santa Cruz, Dallas, TX, USA) was performed on formalin-fixed, paraffin-embedded tissue sections using the EnVision System (DAKO Corp). All tumor specimens were obtained before therapy. Duplicates of $1 \mathrm{~mm}$ diameter cores from the tumor center and noncancerous margin (2 punches, designated as tumor and corresponding normal tissue, respectively) were included in each sample, along with controls, to ensure reproducibility and homogenous staining.
Table I. Patients and treatment characteristics $(n=64)$.

\begin{tabular}{|c|c|c|}
\hline Characteristics & No of cases & $\%$ \\
\hline Age (years), median (range) & $69(49-84)$ & \\
\hline Gender (male/female) & $60 / 4$ & $94 / 6$ \\
\hline \multicolumn{3}{|l|}{ WHO/ECOG PS } \\
\hline PS 0 & 17 & 27 \\
\hline PS 1 & 33 & 52 \\
\hline PS 2 & 14 & 22 \\
\hline \multicolumn{3}{|l|}{ Smoking status } \\
\hline Smokers & 55 & 86 \\
\hline Never smokers & 9 & 14 \\
\hline \multicolumn{3}{|l|}{ Histology } \\
\hline Squamous & 42 & 66 \\
\hline Adenocarcinoma & 12 & 19 \\
\hline Undifferentiated & 10 & 16 \\
\hline \multicolumn{3}{|l|}{ Grade } \\
\hline G1 & 5 & 8 \\
\hline G2 & 34 & 53 \\
\hline G3 & 25 & 39 \\
\hline \multicolumn{3}{|l|}{ Stage } \\
\hline IIIA & 53 & 83 \\
\hline IIIB & 11 & 17 \\
\hline \multicolumn{3}{|l|}{ Chemotherapy } \\
\hline Yes & 42 & 66 \\
\hline No & 22 & 34 \\
\hline \multicolumn{3}{|l|}{ Time of chemotherapy } \\
\hline Sequential & 6 & 9 \\
\hline Concurrent & 36 & 56 \\
\hline \multicolumn{3}{|l|}{ Radiotherapy } \\
\hline Yes & 64 & 100 \\
\hline No & 0 & 0 \\
\hline
\end{tabular}

Tumor specimens were reviewed by two pathologists (I.I. \& D.S) blinded to any clinical information. The expression of E-cadherin, and SDC1 was evaluated by a semiquantitative method, in epithelial (cytoplasmic) and stroma components.

E-cadherin expression. Staining for E-cadherin was graded by comparing it to the staining intensity of the positive control core specimen and the percentage of tumor positive cells stained: grade 0 (no expression or minimal expression with less than $10-25 \%$ of tumor cells stained), grade 1 (26-50\% positive cells), grade 3 (51$75 \%$ positive cells) and grade 4 ( $>75 \%$ positive cells). Scores of $0-$ 3 indicated a negative expression, i.e., impaired expression; and $\geq 3$ indicated a positive expression, i.e., preserved expression. The above scoring criteria were described by Mahler-Araujo et al., 2008 (20). Preserved expression implies that the cells preserve their morphology representing less aggressive tumors.

SDC1 expression. A semi-quantitative immunoreactive scoring system (IRS) was used for the evaluation of the expression of SDC1 (CD 138). Membranous or cytoplasmic staining in cancer cells was considered as a positive result. The staining intensity was visually scored ( 0 , no stain; 1 , weak; 2 , moderate; 3 , strong) and the proportion of positive stained cells of the stromal component were assigned as ( 0 , no stain; $1,1-25 \% ; 2,26-50 \% ; 3,>50 \%)(21)$. For 


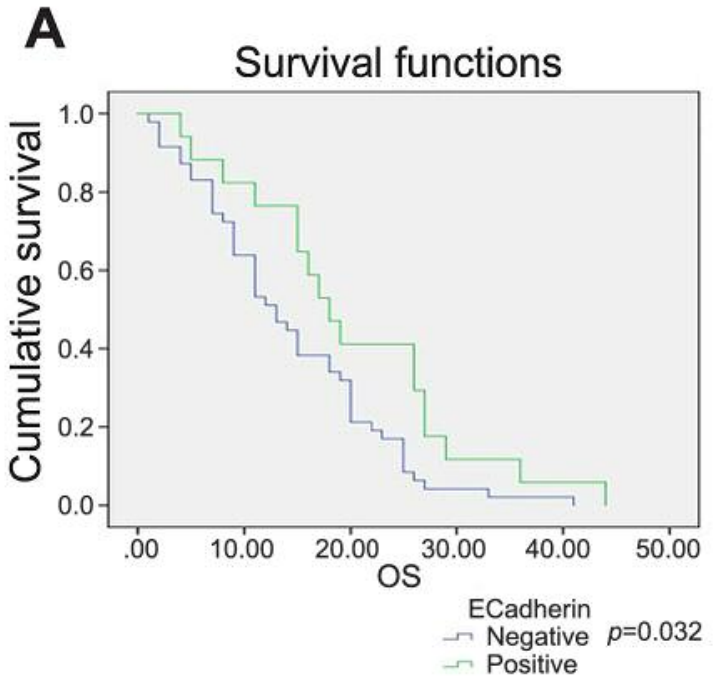

B

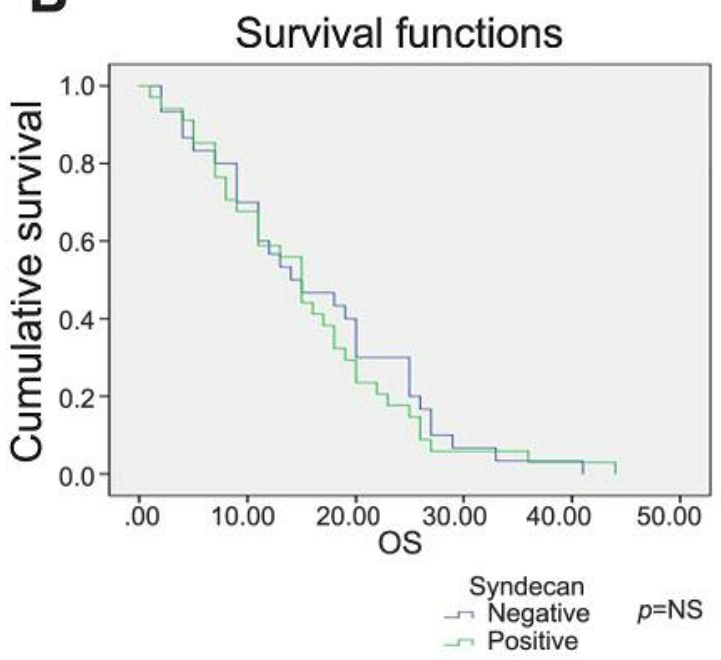

Figure 1. Kaplan-Meier curves of 2-year OS in the cohort correlated with positive and negative expression of E-cadherin (a) and syndecan-1 (b).

the statistical analysis, the level of expression was classified into two groups, considered negative when the score was $0-5$, and positive when the score was $>6$.

Statistical analysis. The relationship of SDC1 and E-cadherin expression with clinicopathological parameters of the patients was assessed using Chi-square and Fisher's exact tests. Spearman's rank correlation was used to analyze the correlations between E-cadherin and SDC1 expression. Study endpoints included overall survival (OS), disease-free survival (DFS), time to locoregional recurrence (LC) and time to distant metastasis (DM).

OS was defined as the time from diagnosis to death from any cause or the last follow up. DFS was defined as time to events including death or disease progression at local, regional or distant sites. The date of progression was defined as the date of radiological or histological confirmation if available, whichever
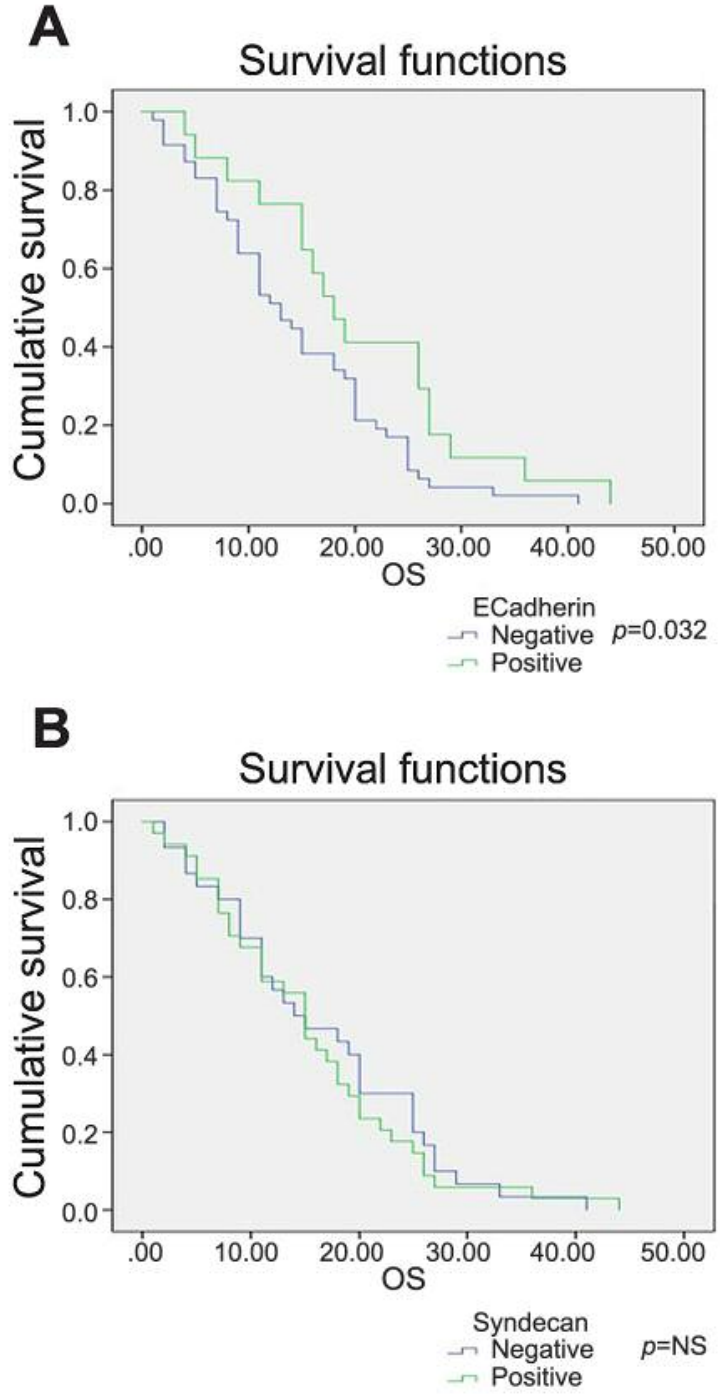

Figure 2. Kaplan-Meier curves of 2-year DFS in the cohort correlated with positive and negative expression of E-cadherin (a) and syndecan-1 (b).

occurred first. LC was defined as the time to documented recurrence in the lung or regional mediastinum lymphadenopathy. DM was defined as the time to documented recurrence in distant sites outside the locoregional sites of disease. Actuarial values of the endpoints were evaluated by the Kaplan-Meier survival analysis and log-rank tests.

Cox univariate analysis was used to determine the prognostic significance of variables, and Cox multivariable analysis was applied to identify independent prognostic factors for NSCLC patients. Cox regression analysis was used for univariate and multivariate analysis and parameters were compared with log-rank tests. $p$-Values of $<0.05$ were considered statistically significant; all $p$-values were two-tailed. All time-related outcomes were calculated from the day of diagnosis. Statistical calculations were performed using SPSS version 21.0 for Windows (IBM, Chicago, IL, USA). 
Table II. Patient and treatment characteristics $(n=64)$.

\begin{tabular}{|c|c|c|c|c|c|c|}
\hline & \multicolumn{3}{|c|}{ OS } & \multicolumn{3}{|c|}{ DFS } \\
\hline & HR & $95 \% \mathrm{CI}$ & $p$-Value & HR & $95 \% \mathrm{CI}$ & $p$-Value \\
\hline $\begin{array}{l}\text { Gender (male } v s . \text { female) } \\
\text { Male } v s . \text { female }\end{array}$ & 1.233 & $0.445-3.415$ & 0.687 & 0.566 & $0.136-2.359$ & 0.434 \\
\hline $\begin{array}{l}\text { Performance status (PS) } \\
0-1 \text { vs. } 2\end{array}$ & 2.851 & $1.835-4.430$ & 0.001 & 2.634 & $1.762-3.897$ & 0.002 \\
\hline $\begin{array}{l}\text { Smoking status } \\
\text { Yes } v s \text {. No }\end{array}$ & 0.777 & $0.389-1.590$ & 0.489 & 0.627 & $0.244-1.611$ & 0.333 \\
\hline $\begin{array}{l}\text { Histology } \\
\quad \text { Squamous } v s \text {. adeno } v s \text {. undifferentiated }\end{array}$ & 1.104 & $0.785-1.553$ & 0.569 & 0.944 & $0.614-1.611$ & 0.333 \\
\hline $\begin{array}{l}\text { Grade } \\
\quad \text { G1 vs. G2 vs. G3 }\end{array}$ & 1.332 & $0.880-2.016$ & 0.175 & 1.422 & $0.866-2.334$ & 0.164 \\
\hline $\begin{array}{l}\text { Chemotherapy } \\
\text { Yes } v s . \text { No }\end{array}$ & 1.702 & $0.998-2.898$ & 0.051 & 1.959 & $1.037-3.702$ & 0.038 \\
\hline $\begin{array}{l}\text { E-cadherin expression } \\
\text { Positive } v s . \text { Negative }\end{array}$ & 1.824 & $1.018-3.266$ & 0.035 & 1.952 & $0.966-3.945$ & 0.062 \\
\hline $\begin{array}{l}\text { Syndecan-1 expression } \\
\text { Positive } v s \text {. Negative }\end{array}$ & 0.897 & $0.546-1.476$ & 0.670 & 0.664 & $0.349-1.187$ & 0.158 \\
\hline
\end{tabular}

Table III. Multivariate analysis.

\begin{tabular}{|c|c|c|c|c|c|c|}
\hline & \multicolumn{3}{|c|}{ OS } & \multicolumn{3}{|c|}{ DFS } \\
\hline & HR & $95 \% \mathrm{CI}$ & $p$-Value & HR & $95 \% \mathrm{CI}$ & $p$-Value \\
\hline $\begin{array}{l}\text { Performance status (PS) } \\
0-1 \text { vs. } 2\end{array}$ & 0.008 & $0.000-0.153$ & 0.001 & 0.004 & $0.000-0.061$ & 0.001 \\
\hline $\begin{array}{l}\text { E-cadherin expression } \\
\text { Positive } v s . \text { Negative }\end{array}$ & 0.48 & $0.234-0.790$ & 0.007 & 0.432 & $0.204-0.832$ & 0.029 \\
\hline
\end{tabular}

\section{Results}

Demographics. A total of 64 patients with inoperable stage III NSCLC were included in the study. The median age at diagnosis was 69 years (range $=49-84$ years). Patient, disease and treatment characteristics are listed in Table I. The median follow-up of patients was 15 months (range=5-44 months).

Relationship between expression of E-cadherin, Syndecan-1 and clinical characteristics of the patients. E-cadherin expression had no statistically significant correlation with any of the clinical or treatment factors. However, male gender, smoking, grade 2 and grade 3 tumors, metastatic patients and squamous cell histology, had mainly negative E-cadherin expression.

Regarding syndecan-1, there was a statistically significant correlation between the negative expression of the molecule and squamous pathology $(p=0.002)$. A statistical correlation between the positive expression of syndecan-1 and negative expression E-cadherin was also found $(\mathrm{R}=0.024, p=0.045)$.
Relationship between expression of E-cadherin, syndecan-1 and patient survival. Positive expression of E-cadherin was significantly associated with increased 2-year OS rate (43.8\% vs. 17.4\%, $p=0.032$ ), (Figure 1a), whereas syndecan1 expression was not significantly associated with survival rates $(30.3 \%$ vs. $20.7 \%, p=0.655)$, (Figure $1 \mathrm{~b}$ ). Although the result was not statistically significant, there was an indication that 2-year DFS rate could be correlated with the positive Ecadherin expression ( $30 \% v s .16 .6 \%, p=0.051)$, (Figure $2 \mathrm{a}$ ), while there was no statistically significant correlation between 2-year DFS rate and the expression of syndecan-1 (33.3\% vs. $11.1 \%, p=0.143$ ), (Figure 2b).

Univariate analysis was performed to examine the impact of various factors on OS and DFS. Performance status (PS) was a significant predictor of OS [Hazard ratio $(\mathrm{HR})=2.851,95 \%$ confidence interval $(\mathrm{CI})=1.835-4.430, p=0.001]$ and DFS $(\mathrm{HR}=0.566,95 \% \mathrm{CI}=1.762-3.897, p=0.002)$. A statistically significant difference in OS was observed, favoring the patients with E-cadherin expression $(\mathrm{HR}=1.824,95 \% \mathrm{CI}=1.018-3.266$, 
$p=0.035$ ), while there was no correlation with DFS in patients with positive $\mathrm{E}$-cadherin expression $(\mathrm{HR}=1.952,95 \% \mathrm{CI}=0.966$ $3.945, p=0.062)$. Additionally, chemotherapy was a significant predictor of DFS $(\mathrm{HR}=1.959,95 \% \mathrm{CI}=1.037-3.702, p=0.038)$, whereas there was no correlation between chemotherapy administration and $\mathrm{OS}(\mathrm{HR}=1.702,95 \% \mathrm{CI}=0.998-2.898$, $p=0.051$ ) (Table II).

In the multivariate Cox analysis, PS 0.1 was an independent predictor of OS $(\mathrm{HR}=0.008,95 \% \mathrm{CI}=0.000$ $0.153, p=0.001)$ and DFS $(\mathrm{HR}=0.004,95 \% \mathrm{CI}=0.000-0.061$, $p=0.001)$. Moreover, E-cadherin expression was an independent predictor of $\mathrm{OS}(\mathrm{HR}=0.48,95 \% \mathrm{CI}=0.234-0.790$, $p=0.007)$ and DFS $(\mathrm{HR}=0.432,95 \% \mathrm{CI}=0.204-0.832$, $p=0.029$ ), while chemotherapy failed to retain the statistical significance observed in the univariate analysis $(p=0.16)$ (Table III).

\section{Discussion}

Although many studies have been conducted about the treatment options of NSCLC, still the prognosis of advanced stage disease remains dismal. A lot of studies have attempted to identify the molecular profile of NSCLC and correlates biological markers to the response to RT and chemotherapy. This retrospective study was performed in order to describe the potential correlation of E-cadherin and syndecan-1 expression, with advanced stage NSCLC treated with RT \pm chemotherapy, and additionally to evaluate if these molecules could be used as prognostic factors for OS and DFS.

Our results showed that positive E-cadherin expression was associated with increased OS, as well as DFS. Selective loss of E-cadherin can cause dedifferentiation and invasiveness in human carcinomas, classifying E-cadherin as a tumor suppressor. Several studies have consistently found a correlation between loss of E-cadherin expression and poor prognosis in lung cancer patients treated with radiotherapy and/or chemotherapy. It was reported that during lung carcinogenesis a reduction in the expression of E-cadherin leads to a strong invasive ability and metastatic potential (22). Recent studies have reported that E-cadherin downregulation is related to stimulation of the growth of the tumor and infiltration $(23,24)$. Furthermore, low expression of Ecadherin in a lung cancer study was associated with increased relapse and poor survival rate (25).

The present study revealed statistically significant correlations between PS, chemotherapy and E-cadherin on OS and DFS. Moreover, PS and E-cadherin expression were estimated to be independent prognostic factors in the multivariate analysis. E-cadherin expression may be a novel prognostic marker for NSCLC patients in terms of progression and survival.

Reduced or absent expression of E-cadherin has been thought to play a role in NSCLC, which may be associated with uncontrolled cell proliferation, and increased tumor vascularization. The above changes in the tumor microenvironment could possibly explain the faster growth and larger size of the aggressive subtypes of NSCLC (23, 26). Notably, our results highlight the complex role of the cell-adhesion system in carcinogenesis. Reduced expression of E-cadherin and increased expression of SDC1 may be correlated with dismal prognosis due to loss of epithelial morphology and cell to cell and cell to matrix adhesion.

Regarding SDC1, few studies have investigated its expression in NCSLC, with conflicting results. In a study by Toyoshima et al., increased SDC1 levels did not correlate with OS (27), while in recent studies, reported strong expression of SDC1 in operable squamous cell lung carcinoma, correlated with low grade tumours and a favourable prognosis (19). Our results showed a statistically significant correlation between SDC1 expression and squamous histological type $(p=0.002)$, mirroring findings from a prior study that evaluated the levels of the protein in the squamous cell subtype (19). Given the fact that SDC1 degradation is linked to the invasiveness of several cancers, to some extent, loss of SDC1 expression in NSCLC may be associated with high metastatic potential and more aggressive tumours $(28,29)$. Supporting the previous comment, in a recent study, the loss of SDC1 expression in patients with colorectal cancer was associated with aggressive behavior and poor outcome (30). Additionally, in some experimental studies, it has been shown that SDC1 expression is associated with the maintenance of epithelial morphology, and the inhibition of invasiveness in vitro $(4,14,15,31)$.

The most important limitation of the present study is its retrospective design. Nevertheless, although there was a comparatively small number of patients analyzed, patients were treated relatively consistently and data were collected during a meticulous follow-up.

In summary, to our knowledge, this study is the first to evaluate the expression of E-cadherin and SDC1 in NSCLC patients. E-cadherin might be a prognostic factor for OS and DFS in advanced stage NSCLC patients. Additionally, concerning histological subtypes, squamous cell cancer may express SDC1.

\section{Conflicts of Interest}

The Authors declare no conflicts of interest regarding this study.

\section{Authors' Contributions}

E.B., P.T., D.M. conceived the idea, planned the experiments and shaped the research. S.M. and I.S. contributed to sample preparation. E.I and A.D. carried out the laboratory work. E.P., D.M. and P.G. took the lead to the statistics and analyzed the data. E.P. and P.G. took the lead in writing the manuscript. All Authors provided critical feedback and approved the final manuscript. 


\section{References}

1 Global Burden of Disease Cancer C, Fitzmaurice C, Allen C, Barber RM, Barregard L, Bhutta ZA, et al: Global, regional, and national cancer incidence, mortality, years of life lost, years lived with disability, and disability-adjusted life-years for 32 cancer groups, 1990 to 2015: A systematic analysis for the global burden of disease study. JAMA Oncol 3: 524-548, 2017. PMID: 27918777. DOI: 10.1001/jamaoncol.2016.5688

2 Auperin A, Le Pechoux C, Rolland E, Curran WJ, Furuse K, Fournel P, Belderbos J, Clamon G, Ulutin HC, Paulus R, Yamanaka T, Bozonnat MC, Uitterhoeve A, Wang X, Stewart L, Arriagada R, Burdett S and Pignon JP: Meta-analysis of concomitant versus sequential radiochemotherapy in locally advanced non-small-cell lung cancer. J Clin Oncol 28: 21812190, 2010. PMID: 20351327. DOI: 10.1200/JCO.2009.26.2543

3 Kalluri $\mathrm{R}$ and Weinberg RA: The basics of epithelialmesenchymal transition. J Clin Invest 119: 1420-1428, 2009. PMID: 19487818. DOI: 10.1172/JCI39104

4 Kato M, Saunders S, Nguyen H and Bernfield M: Loss of cell surface syndecan-1 causes epithelia to transform into anchorageindependent mesenchyme-like cells. Mol Biol Cell 6: 559-576, 1995. PMID: 7545031. DOI: 10.1091/mbc.6.5.559

5 Warrington SJ, Strutt H and Strutt D: The Frizzled-dependent planar polarity pathway locally promotes E-cadherin turnover via recruitment of RhoGEF2. Development 140: 1045-1054, 2013. PMID: 23364328. DOI: 10.1242/dev.088724

6 Halbleib JM and Nelson WJ: Cadherins in development: cell adhesion, sorting, and tissue morphogenesis. Genes Dev 20: 3199-3214, 2006. PMID: 17158740. DOI: $10.1101 / \mathrm{gad}$. 1486806

7 Muller S, Su L, Tighiouart M, Saba N, Zhang H, Shin DM and Chen Z: Distinctive E-cadherin and epidermal growth factor receptor expression in metastatic and nonmetastatic head and neck squamous cell carcinoma: predictive and prognostic correlation. Cancer 113: 97-107, 2008. PMID: 18473353. DOI: $10.1002 /$ cncr. 23557

8 Miyanaga A, Gemma A, Ando M, Kosaihira S, Noro R, Minegishi Y, Kataoka K, Nara M, Okano T, Miyazawa H, Tanaka T, Yoshimura A, Kobayashi K, Iwanami H, Hagiwara $\mathrm{K}$, Tsuboi E and Kudoh S: E-cadherin expression and epidermal growth factor receptor mutation status predict outcome in nonsmall cell lung cancer patients treated with gefitinib. Oncol Rep 19: 377-383, 2008. PMID: 18202784.

9 Lee JM, Dedhar S, Kalluri R and Thompson EW: The epithelialmesenchymal transition: new insights in signaling, development, and disease. J Cell Biol 172: 973-981, 2006. PMID: 16567498. DOI: $10.1083 /$ jcb. 200601018

10 Thiery JP: Epithelial-mesenchymal transitions in tumour progression. Nat Rev Cancer 2: 442-454, 2002. PMID: 12189386. DOI: $10.1038 / \mathrm{nrc} 822$

11 Cheung KJ and Ewald AJ:A collective route to metastasis: Seeding by tumor cell clusters. Science 8: 167-169, 2016. PMID: 27124449. DOI: 10.1126/science.aaf6546

12 Son $\mathrm{H}$ and Moon A: Epithelial-mesenchymal transition and cell invasion. Toxicol Res 26: 245-252, 2010. PMID: 24278531. DOI: $10.5487 /$ TR.2010.26.4.245

13 Garusi E, Rossi S and Perris R: Antithetic roles of proteoglycans in cancer. Cell Mol Life Sci 69: 553-579, 2012. DOI: 10.1007/s00018-011-0816-1
14 Bernfield M, Gotte M, Park PW, Reizes O, Fitzgerald ML, Lincecum $\mathrm{J}$ and Zako M: Functions of cell surface heparan sulfate proteoglycans. Annu Rev Biochem 68: 729-777, 1999. PMID: 10872465. DOI: 10.1146/annurev.biochem.68.1.729

15 Volk R, Schwartz JJ, Li J, Rosenberg RD and Simons M: The role of syndecan cytoplasmic domain in basic fibroblast growth factor-dependent signal transduction. J Biol Chem 274: $24417-$ 24424, 1999. DOI: $10.1074 /$ jbc 274.34 .24417

16 Kwon MJ, Jang B, Yi JY, Han IO and Oh ES: Syndecans play dual roles as cell adhesion receptors and docking receptors. FEBS Letters 586: 2207-2211, 2012. PMID: 22659189. DOI: 10.1016/j.febslet.2012.05.037

17 Lambaerts K, Wilcox-Adelman SA and Zimmermann P: The signaling mechanisms of syndecan heparan sulfate proteoglycans. Curr Opin Cell Biol 21: 662-669, 2009. PMID: 19535238. DOI: 10.1016/j.ceb.2009.05.002

18 Palaiologou M, Delladetsima I and Tiniakos D: CD138 (syndecan1) expression in health and disease. Histol Histopathol 29: 177189, 2014. PMID: 24150912. DOI: 10.14670/HH-29.177

19 Anttonen A, Heikkila P, Kajanti M, Jalkanen M and Joensuu H: High syndecan-1 expression is associated with favourable outcome in squamous cell lung carcinoma treated with radical surgery. Lung Cancer 32: 297-305, 2001. PMID: 11390011. DOI: $10.1016 / \mathrm{s} 0169-5002(00) 00230-0$

20 Mahler-Araujo B, Savage K, Parry S and Reis-Filho JS: Reduction of E-cadherin expression is associated with nonlobular breast carcinomas of basal-like and triple negative phenotype. J Clin Pathol 61: 615-620, 2008. PMID: 18156431. DOI: $10.1136 /$ jcp.2007.053991

21 Kim SY, Choi EJ, Yun JA, Jung ES, Oh ST, Kim JG, Kang WK and Lee SH: Syndecan-1 expression is associated with tumour size and EGFR expression in colorectal carcinoma: a clinicopathological study of 230 cases. Int J Med Sci 12: 92-99, 2015. PMID: 25589885. DOI: 10.7150/ijms.10497

22 He LY, Zhang H, Wang ZK and Zhang HZ: Diagnostic and prognostic significance of E-cadherin and Ki-67 expression in non-small cell lung cancer patients. Eur Rev Med Pharmacol Sci 20: 3812-3817, 2016. PMID: 27735037.

23 Farmakovskaya M, Khromova N, Rybko V, Dugina V, Kopnin $\mathrm{B}$ and Kopnin P: E-Cadherin repression increases amount of cancer stem cells in human A549 lung adenocarcinoma and stimulates tumor growth. Cell Cycle 15: 1084-1092, 2016. PMID: 26940223. DOI: 10.1080/15384101.2016.1156268

24 Dursun P, Yuce K, Usubutun A and Ayhan A: Loss of epithelium cadherin expression is associated with reduced overall survival and disease-free survival in early-stage squamous cell cervical carcinoma. Int J Gynecol Cancer 17: 843-850, 2007. DOI: 10.1136/ijgc-00009577-200707000-00014

25 Wang G, Ma W, Li Y, Jiang Y, Ma G, Zhang X, Meng L and Du $\mathrm{J}$ : Prognostic value of Twist, Snail and E-cadherin expression in pathological N0 non-small-cell lung cancer: a retrospective cohort study. Eur J Cardiothorac Surg 54: 237-245, 2018. PMID: 29415155. DOI: 10.1093/ejcts/ezy022

26 Luo T, Wang L, Wu P, Gong W, Chen W, Zhao H and Zheng Z: Downregulated vimentin and upregulated E-cadherin in T1 stage non-small-cell lung cancer: does it suggest a mesenchymalepithelial transition? Neoplasma 64: 693-699, 2017. PMID: 28592120. DOI: 10.4149/neo_2017_506

27 Toyoshima E, Ohsaki Y, Nishigaki Y, Fujimoto Y, Kohgo Y and Kikuchi K: Expression of syndecan-1 is common in human lung 
cancers independent of expression of epidermal growth factor receptor. Lung Cancer 31: 193-202, 2003. PMID: 11165398. DOI: $10.1016 / \mathrm{s} 0169-5002(00) 00184-7$

28 Hirabayashi K, Numa F, Suminami Y, Murakami A, Murakami $\mathrm{T}$ and Kato $\mathrm{H}$ : Altered proliferative and metastatic potential associated with increased expression of syndecan-1. Tumour Biol 19: 454-463, 1998. DOI: 10.1159/000030037

29 Szatmari T, Mundt F, Heidari-Hamedani G, Zong F, Ferolla E, Alexeyenko A, Hjerpe A and Dobra K: Novel genes and pathways modulated by syndecan-1:implications for the proliferation and cell-cycle regulation of malignant mesothelioma cells. PLoS One 7: e48091, 2012. PMID: 23144729. DOI: 10.1371/journal.pone. 0048091

30 Mitselou A, Galani V, Skoufi U, Arvanitis DL, Lampri E and Ioachim E: Syndecan-1, Epithelial-mesenchymal transition markers (E-cadherin/ $\beta$-catenin) and neoangiogenesis-related proteins (PCAM-1 and Endoglin) in colorectal cancer. Anticancer Res 36: 2271-2280, 2016. PMID: 27127133.
31 Shah L, Walter KL, Borczuk AC, Kawut SM, Sonett JR, Gorenstein LA, Ginsburg ME, Steinglass KM and Powell CA: Expression of syndecan-1 and expression of epidermal growth factor receptor are associated with survival in patients with nonsmall cell lung carcinoma. Cancer 101: 1632-1638, 2004. PMID: 15378500. DOI: 10.1002/cncr.20542

Received September 30, 2019 Revised November 2, 2019 Accepted November 4, 2019 